\title{
Seismic Imaging for 3-D RVSP Data Using Image Point Transform
}

\author{
Changhyun Lee ${ }^{1}$, Toshiyuki Matusoka ${ }^{2}$, Koichi Ishigaki ${ }^{2}$, Masayoshi Tanoue ${ }^{3}$, \\ Shinji Yamaguchi ${ }^{4}$, Terumitsu Tsuchiya ${ }^{5}$, Toshifumi Matusoka ${ }^{1}$ \\ ${ }^{1}$ Dept. of Civil and Earth Resource Eng., Kyoto University \\ 2 Japan Atomic Energy Agency \\ 3 Dia-Consultans Co., Ltd \\ ${ }^{4}$ Niho-Chikatansa Co., Ltd \\ ${ }^{5}$ Arabian Oil Co., Ltd
}

\begin{abstract}
Image Points are defined through geometry of sources, receivers and reflectors. IP (Image Point) transform is one type of Radon transform which change common shot section to IP domain(r-x). By the IP transform, reflection signals in time domain can be accumulated and enhanced in IP domain.

We applied the IP transform to the field data of RVSP that had been carried out at the Mizunami Underground Research Laboratory(MIU) site. We could get the fault image around the MIU site using IP transform.
\end{abstract}

\section{Introduction}

Last year, we addressed the seismic imaging using image point(IP) transform for the numerical simulation data.(Lee et al, 2006) In this study, we apply the IP transform imaging for the field data of reverse vertical seismic(RVSP) that are observed at the Mizunami Underground Research Laboratory (MIU) site.

\section{(1) Field Explanation}

The MIU site is located in Mizunami city, Gifu, central Japan. In this area, the basement rock is Cretaceous granite(Toki granite) and Neocene sedimentary rocks(Mizunami group and Seto group) cover the Toki granite. Here, two shafts(Main: $\phi 6.5 \mathrm{~m}$, Ventilation: $\phi 4.5 \mathrm{~m}$ ) and several level drifts are planed to be excavated to the $1000 \mathrm{~m}$ depth for research into deep underground environments as a part of the $R \& D$ related to geological disposal of high-level radioactive waste (Fig.1).

\section{(2) Data acquisition}

The explosions of dynamite for excavation of the main shaft are used as seismic sources and 174 receivers are located around the main shaft (Fig 2).
Four shot data were acquired until now (Table 1).

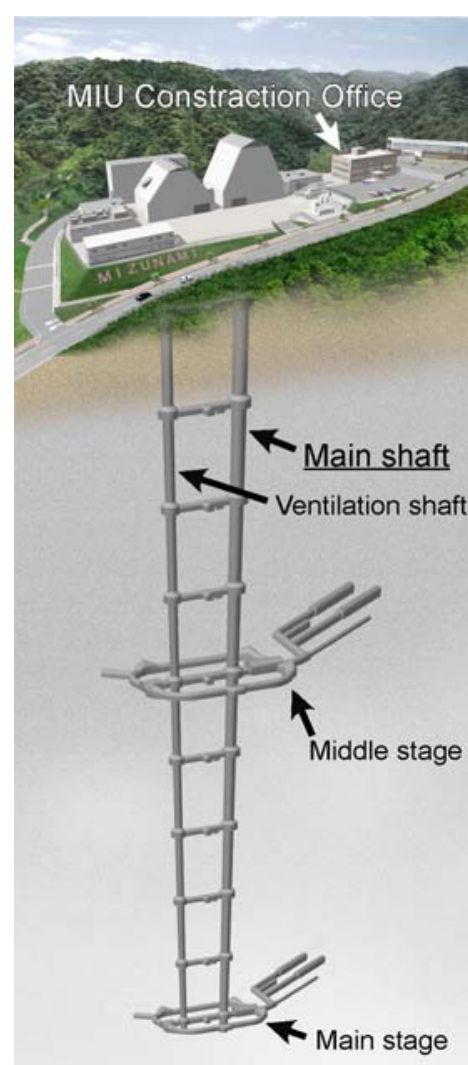

Fig. 1 Schematic diagram of Mizunami Underground Laboratory project. 
Table 1 Summary of the data acquisition.

\begin{tabular}{|c|c||c|c|}
\hline $\begin{array}{c}\text { Receiver } \\
\text { Line }\end{array}$ & $\begin{array}{c}\text { Channel } \\
\text { No. }\end{array}$ & $\begin{array}{c}\text { Shot } \\
\text { No. }\end{array}$ & $\begin{array}{c}\text { Depth from } \\
\text { the ground level }\end{array}$ \\
\hline Line 1 & $1-22$ & Shot 1 & $-81 \mathrm{~m}$ \\
\hline Line 2 & $23-37$ & Shot 2 & $-106 \mathrm{~m}$ \\
\hline Line 3 & $38-64$ & Shot 3 & $-136 \mathrm{~m}$ \\
\hline Line 4 & $65-124$ & Shot 4 & $-152 \mathrm{~m}$ \\
\hline Line 5 & $125-144$ & & \\
\hline Line 6 & $145-174$ & & \\
\hline
\end{tabular}

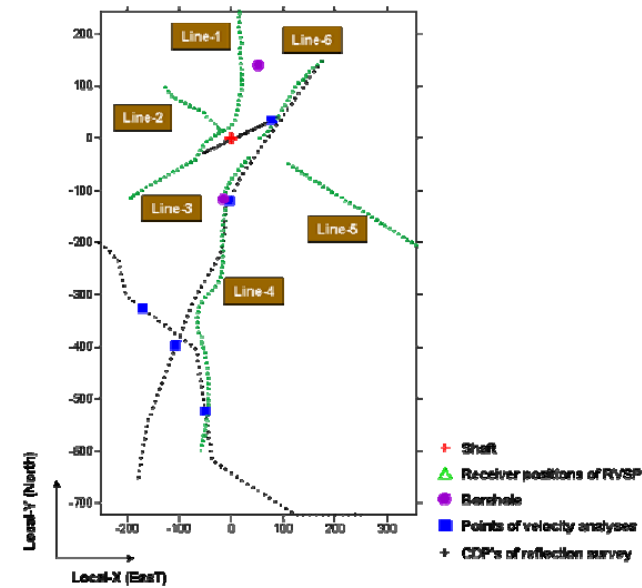

Fig. 2 Plan view of receiver geometry.

\section{IP transform and Imaging}

Fig. 3 shows an example of common shot record (Band pass filter, shot-time correction, elevation correction and AGC are applied).

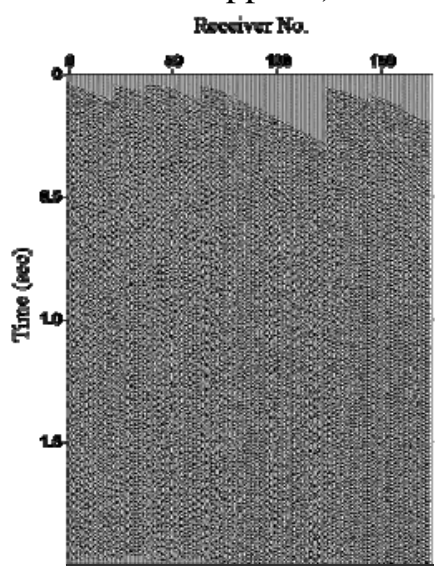

Fig. 3 Common shot record (Shot 1)

In numerical test, we addressed that the image point of one reflector was enhanced on the IP domain whose direction was perpendicular to the reflection plane (Lee et al, 2005).

The existing information helps us to confine the IP transform ranges. Fault distributions are inferred from the previous investigations (e.g. reflection seismic survey, borehole investigation, surface geological survey). Fig.4 shows IP transform axes whose directions are perpendicular to strike of inferred faults.

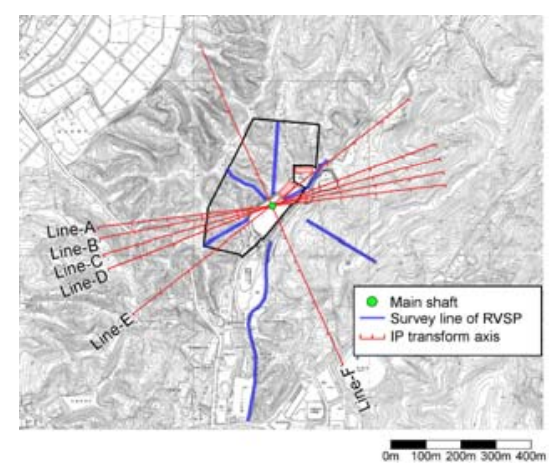

Fig. 4 IP transform axes and RVSP receiver lines.

The results of 2D imaging sections of each axis line are presented in Fig 5.

We could get 2D images which agree with the fault location except for Line-F. The reason of disagreement of Line-F can be explained by the fact that fault is located too far from the seismic source and the power is too lower to detect the reflector.

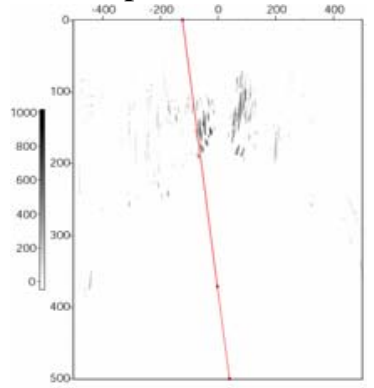

(a) Line-A

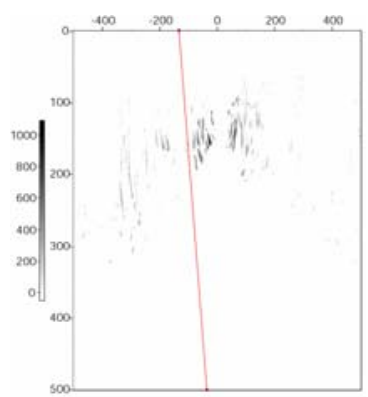

(c) Line-C

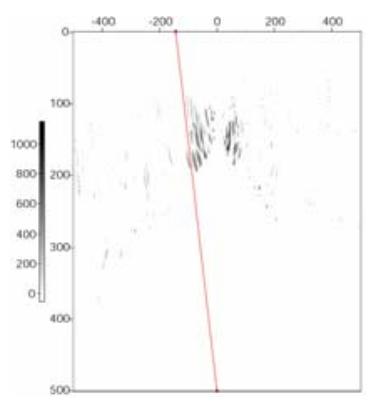

(e) Line-E

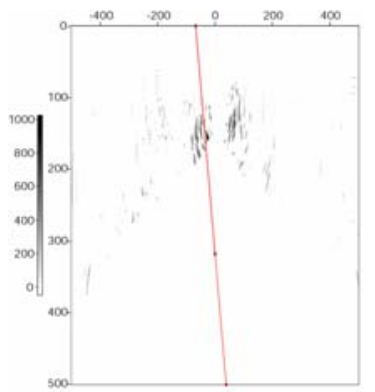

(b) Line-B

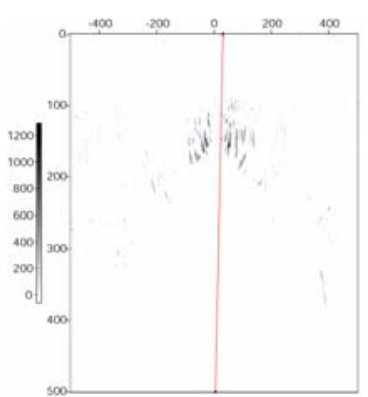

(d) Line-D

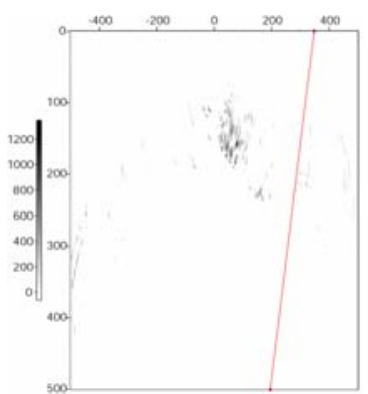

(f) Line-F
Fig 5 2D imaging result 


\section{REFERENCES}

1) C. Lee, T. Matsuok, K. Ishigaki, M. Tanoue, N. Narita, M. Kojima, T. Tsuchiya, T. Matsuoka, 2006, Seismic imaging for 3-D VSP data using image point transform., The 10th International Symposiumon Recent Advances in Exploration Geophysics, 143-147.

2) Cosma, C and Heikkinen, P., 1996, Seismic investigations for the final disposal of spent nuclear fuel in Finland, J. Applied Geophysics., 35, 151-157.

3) Enescu, N., McDowell, G.M., Cosma, C and Bell, C : Crosshole seismic investigation at Voisey's Bay, Canada, SEG Expand Abstract. ,V21, pp. 1472, 2002.

4) Van Schaack, M., Harris, J. M., Rector, J. W., and Lazaratos, S. K., 1995, High resolution crosswell imaging of a West Texas carbonate reservoir, Part 2-Wavefield modeling and analysis: Geophysics, 60, 682-691.

5) Wyatt, K. D., and Wyatt, S. B., 1981, Determination of subsurface structural information using the vertical seismic profile: 51st Ann. Internat. Mtg., Soc. Expl. Geophys., Expanded Abstracts, 1915-1549. 